\title{
Peertechz
}

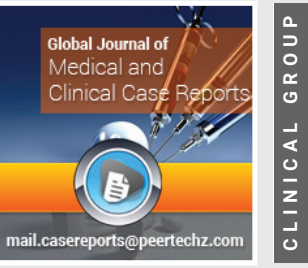

\section{Gastric Volvulus - A Rare Entity}

\author{
Atta Ur Rehman*, Mobeen Ikram and Abdul Rauf \\ College of Physians and Surgeons, Pakistan
}

Received: 14 October, 2020

Accepted: 26 October, 2020

Published: 27 October, 2020

*Corresponding author: Atta Ur Rehman, College of Physians and Surgeons, Pakistan, Tel: 03363355446 ; E-mail: ata_1702@yahoo.com

Keywords: Borchardt triad; Gastric Volvulus; Pain epigastrium; Retching

https://www.peertechz.com

\begin{abstract}
Gastric volvulus is seldom seen in clinical practice. The clinical triad, of upper abdominal pain, intractable retching and inability to pass nasogastric (NG) tube, if found, can help in diagnosis. It can lead to gangrene and perforation of the stomach if remained undiagnosed or treated late. Both acute and chronic presentation is seen. The chronic form is more common than acute clinical presentation but the latter is associated with more complications. Laxity of gastric ligaments, made up of peritoneal folds is responsible for this condition. The knowledge of the condition, timely diagnosis and early surgical management is essential for a favourable outcome as done in the case being presented.
\end{abstract}

\section{Introduction}

Gastric volvulus, a rare clinical condition, is the twist or rotation of stomach either along its long axis (organo-axial type) or horizontal axis (mesentero-axial type) leading to upper gastrointestinal obstruction. Laxity of two or more of four ligaments of the stomach, hiatal hernia, and defects of the diaphragm are the most frequent predisposing factors. It is found both in children and adults, usually in old age. It can present with acute or chronic symptoms. The diagnosis is based on clinical and radiological findings. In an acute presentation, mesentero-axial type is most frequently seen which needs prompt surgical intervention to avoid complications like gangrene, perforation or fatal outcome.

\section{Case report}

A 61-year-old fragile male presented to our hospital with sudden onset pain upper abdomen about 48 hours duration. The pain started when he was stooping forward after a heavy dinner. His abdomen was distended and the discomfort continued aggravating over the next two days. He constantly felt to vomit but he remained unable to do so. The nature of pain was gripping to start with later changed to constant dull throbbing pain. Any attempt to vomit, failed. He could not tolerate anything to drink or eat.

His condition deteriorated since the onset of symptoms. He was referred to our hospital. His past history was insignificant. There was no history of dyspepsia, use of NSAIDs or any operation previously.
On general physical examination, he was a thin built, dehydrated aged individual with a pulse of $104 / \mathrm{min}$, temperature $100.2^{\circ} \mathrm{F}$. He was pale looking and in distress. His skin was thin and fragile. Abdominal inspection revealed protuberance of the abdomen more marked in epigastrium (Figure 1). It was slightly tender to touch. Bowel sounds were normal. The abdomen was tympanatic/ resonant on percussion. Digital Rectal Examination (DRE) and the rest of the examination was unremarkable.

He was managed with intravenous fluids, antibiotics and analgesics. Nasogastric (NG) tube was passed; size 10 was the smallest that could be passed. That too was pulled out by the patient. Later attempts were unsuccessful to pass. His $\mathrm{Hb}$ was $11.6 \mathrm{gm} \%$; TLC was $12.3 \times 10 \%$ L with $78 \%$ neutrophils.

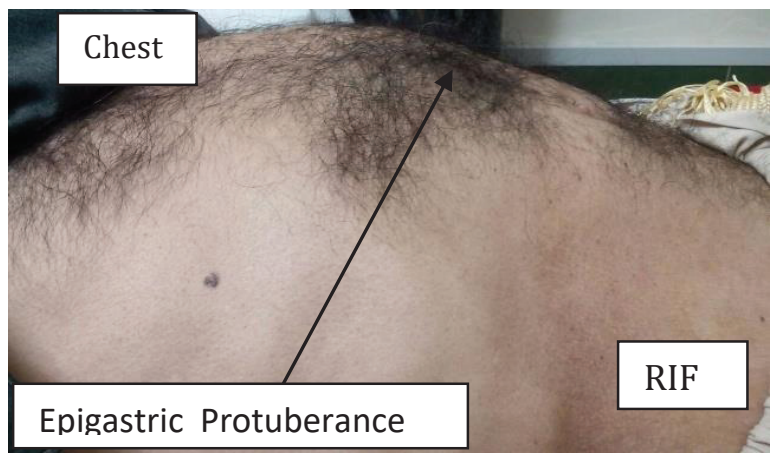

Figure 1: Upper abdominal distension (protuberance). 
Hepatitis B \& C screening was negative. The X-ray revealed a double shadow in the gastric region with marked dilatation of the stomach outline. Left hemi diaphragm was raised (Figure 2). There was hardly any gas in intestines (Figure 3). We did not have contrast studies at our remote primary care hospital. The short history and the presence of pertinent clinical signs, contrast barium studies were neither required in this patient nor we asked for. The condition of the patient did not improve over 6 hours. It was decided to undertake laparotomy. Informed written consent was taken for it.

At operation, it was found that the stomach, with mesentero-axial volvulus, was enormously distended (Figure 4). As NG tube could not be passed until it was derotated. On de-rotation, the stomach was easily decompressed with, NG tube insertion. The serosal surfaces of the stomach had some areas of patchy blackish discoloration but left in -situ, due to absence of signs of obvious gangrene (Figure 5). The serosaguis fluid, about one litre was drained out of the peritoneal cavity. Lesser omentum was very lax and enormously large. The anterior wall of the stomach was fixed with three sutures to the posterior surface of the anterior abdominal wall. Laparotomy wound was easily closed without a drain.

Oral fluids were started the next morning. Fluids were tolerated well, so in the evening he was allowed full oral diet. He was discharged on $4^{\text {th }}$ post day and stitches were removed on $12^{\text {th }}$ post-op day. Since then he is living with no abdominal complaints.

\section{Discussion}

The twisting of the stomach, the gastric Volvulus, on itself is a rare occurrence. The origin of the term volvulus is from a Latin word 'volvere' which means to roll or turn. The condition was first noticed in 1866 by Brits during a post mortem examination and the first treated case was published by Berg in 1897 [1]. By definition, it is the rotation of the stomach more than $180^{\circ}$ around its longitudinal or horizontal axis, leading to organo-axial and mesentero- axial volvulus, respectively. The

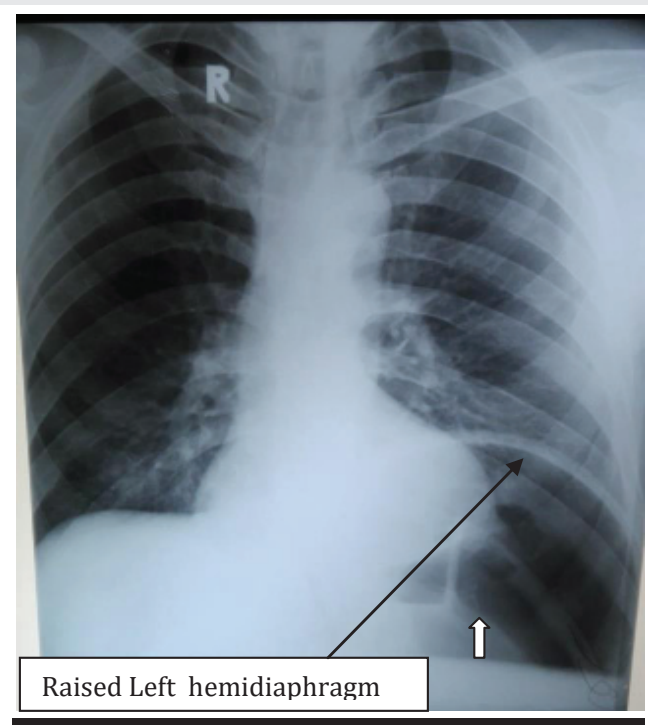

Figure 2: Chest X-ray with elevated hemidiaphrag and double density shadow (White arrow)

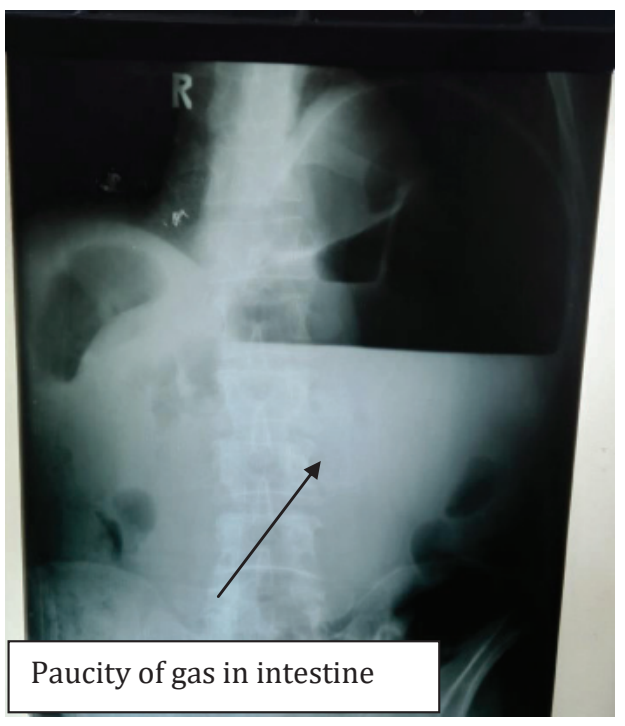

Figure 3: X- ray Abdomen.

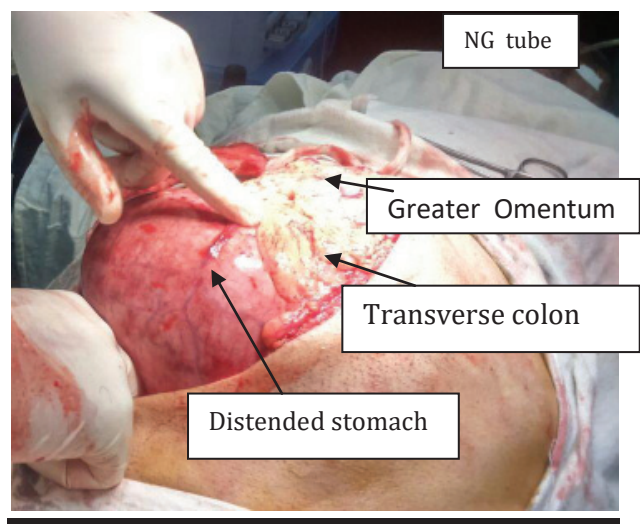

Figure 4: Operative Appearance of distended stomach.

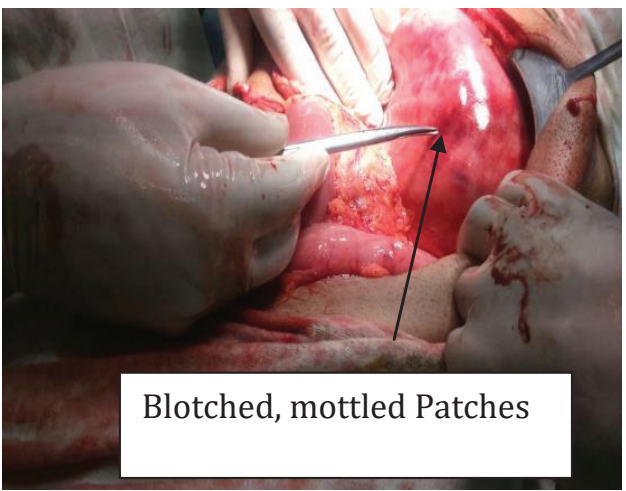

Figure 5: Blotching of gastric wall, left to heal as such.

normal stomach is stabilized by different ligaments, for more than $180^{\circ}$ rotation, gastro-colic and gastro-splenic ligaments have to be cut or very relaxed [2]. In 1904 Borchardt described a triad of symptoms for it, comprising of severe upper abdominal pain, persistent retching and inability to pass NG tube. Any forceful attempt to pass NG tube can result in perforation of esophagus or stomach. This triad is seen in about $70 \%$ of patients [3]. 
The most common viscus to undergo volvulus is sigmoid colon, followed by caecum, small intestine. Gastric volvulus is rare. Its rarity can be witnessed by the fact that a few case series are found in the literature. Largest series was with 38 cases over 34 years $^{1}$ [4], followed by 36 cases [5]. From Pakistan, about 17 case reports are available so far. It occurs mostly in the $5^{\text {th }}$ to $6^{\text {th }}$ decade of life. One case of gastric volvulus with pyloric stenosis in a child is recently reported [6]. There are about 500 cases reported in English literature in the past 150 years since the recognition of this condition. Animals' cases have been reported, too $[7,8]$.

It can present in either acutely as seen in this case or chronically [9]. Acute presentation accounts for $1 / 3^{\text {rd }}$ of cases and $2 / 3^{\text {rd }}$ present as chronic cases [10]. In the largest case series so far $90 \%$ presented with chronic symptoms and $10 \%$ with sudden onset of pain Jacob. Majority of chronic symptoms present with the mesentero-axial type of volvulus ${ }^{1}$. Chronic cases present with dyspepsia, which is relieved over a few days due to the reversal of the phenomenon $[11,12]$. The atypical presentation can be seen [13]. But a time comes when the twist in the stomach cannot be undone, necessitating the surgical management. Respiratory and cardiac compromise is associated with large volvulus [14].

The lax gastric ligaments and the presence of diaphragmatic defect are predisposing factors. It can present as haemoperitoneum [15]. Gastric volvulus is also been reported in traumatic diaphragmatic rupture, congenital hernias and postoperatively $[16,17]$. There are few cases which were complicated by gastric volvulus after Nissen fundoplication. It is found that a full stomach is more prone to volvulus [18].

In the early decades of the $20^{\text {th }}$ century with the advent of $\mathrm{X}$-rays, it was extensively studied. It was classified by Singleton in three types. Organo-axial and mesentero- axial or combined volvulus. Their ratio of occurrences is 6:3:1, respectively. Due to fixity of the gastro-oesophagal junction and pylorus, the whole of stomach rotates around the longitudinal axis in anticlockwise fashion, bringing the greater curvature anteriorly, with single large blind loop. In the final position, the greater curvature is a cephalad position and the lesser curvature in a caudal position. A hiatal hernia can be complicated by this condition [19].

In mesentero-axial volvulus, the stomach rotates around a trans-gastric axis, bisecting it at lesser and greater curvature, like a balloon twisting and making two separate parts. The fundus goes down and antrum lies supero-medial (right side) to it. Spontaneous derotation may occur. The chronic gastric volvulus is usually of this type.

Radiologically, the organo- axial volvulus appears as a single large air-filled balloon with one air-fluid level, either in abdomen tenting the left hemi-diaphragm or within the thorax depending upon the presence or absence of the diaphragmatic defect, para-oesophagal hernia [20]. Both the cardia and pylorus are seen adjacent to each other. In mesentero- axial type there are two air-fluid levels, the smaller one formed by antrum and pylorus, positioned above and to the right of the larger shadow of air-fluid, depicting the dilated antrum. These features are variable depending upon the extent of the volvulus [21].

Computed tomography (CT) is increasingly used in diagnosing this condition [22]. CT scan is a valuable investigational tool in diagnosing doubtful cases [23]. The diagnosis must be established before the onset of lifethreatening complications. There are multiple merits of CT scan including detection of gastric pneumatosis, predisposing factors like hernia, diaphragmatic defects, adhesions and revealing the other causes of abdominal pain in the absence of volvulus [24].

Strangulation, Gangrene and perforation are dreadful complications which can end with gastrectomy and Rouxen-Y esophago-jejunostomy or even death [25]. Due to rich blood supply gangrene occurs in about 5 to $10 \%$ of cases. The mortality is double for cases who present with acute volvulus as compare to chronic cases. Complications are higher in Organoaxial, the most common type of volvulus. Overall mortality is reduced with better radiological studies and early recognition of the condition [26].

It is managed surgically; Sooner the better [27]. Recurrence rates are variable. Simple derotation, anterior gastropexy or sometimes in late presenting cases partial or total gastrectomy is needed [28]. Presently, it is popularly managed laparoscopically with promising results. The limitations of laparoscopic surgery perforation and massively distended stomach which precludes the laparoscopy. Successful endoscopic management in a geriatric patient has been reported $[29,30]$. Both, laparoscopic and endoscopic modalities are being used with increasing success [31].

\section{References}

1. Lopez PP, Megha R (2020) Gastric Volvulus. 2020 Aug 22. In: StatPearls [Internet]. Treasure Island (FL): StatPearls Publishing. Link: https://bit.ly/3kıOszz

2. Khan AA, Khan AU, Kupec JT (2020) Organoaxial Gastric Volvulus. Clin Gastroenterol Hepatol. Link: https://bit.ly/2TnalZ7

3. Murat K, Nurdan F (2016) A Rare Cause for Acute Abdomen: Gastric VolvulusCase Report. Open Access J Surg 1: 1-4. Link: https://bit.ly/2TnSgdp

4. Jacob CE, Lopasso FP, Zilberstein B, Bresciani CJC, Kuga R, et al. (2009) Gastric volvulus - A review of 38 cases. Brazilian Archives of Digestive Surgery 22: 96-100. Link: https://bit.ly/3mu8VIR

5. Light D, Links D, Griffin M (2016) The threatened stomach: management of the acute gastric volvulus. Surg Endosc 30:1847-1852. Link: https://bit.ly/3jBGy90

6. Da Costa KM, Saxena AK (2019) Management and outcomes of gastric volvulus in children: a systematic review. World J Pediatr 15: 226-234. Link: https://bit.ly/34rnvuh

7. Hammer M, Grand JG (2019) Gastric dilatation and volvulus in a 5-month-old Bernese mountain dog. Can Vet J 60: 587-590. Link: https://bit.ly/2HyOV8z

8. Paravicini PV, Gates K, Kim J (2019) Gastric Dilatation Organoaxial Volvulus in a Dog. J Am Anim Hosp Assoc 56: 42-47. Link: https://bit.ly/3kwguOx

9. Maamouri N, Kchir H, Issaoui D, Ben Safta Z, Ben Mami N (2018) Chronic gastric volvulus. Tunis Med 96: 393-396. Link: https://bit.ly/35v2IL8 
10. Pak K, Junga Z, Young P (2020) An Acute Presentation of Chronic Gastric Volvulus. ACG Case Rep J 7: e00297. Link: https://bit.ly/2TnC0Jg

11. Patel AV, Senatore FJ, Bhurwal A (2019) Epigastric Pain due to Acute Gastric Volvulus. J Emerg Med 57: e185-e186. Link: https://bit.ly/3oufUmE

12. Jervis MJ, Candeias R, Duro E, Pereira LG, Caratão F (2020) Chronic gastric volvulus-Case report of an uncommon diagnosis. Int J Surg Case Rep 66: 139 142. Link: https://bit.ly/37Veqwb

13. Etienne D, Ona MA, Reddy M (2017) Atypical Presentation of Gastric Volvulus. Gastroenterology Res 10: 147-148. Link: https://bit.ly/3dYPWTJ

14. Umemura A, Suto T, Fujiwara H, Ikeda K, Nakamura S, et al. (2019) Cardiopulmonary Impairments Caused by a Large Hiatal Hernia with Organoaxial Gastric Volvulus Showing Upside-Down Stomach: A Case Report. Am J Case Rep 20: 1530-1535. Link: https://bit.ly/3dX56bX

15. Merichal M, Tur J, Melé J, Olsina JJ (2020) Acute abdomen with hemoperitoneum: A rare manifestation of gastric volvulus. Cir Esp 98: 160. Link: https://bit.ly/31GasDG

16. Zain M, Abada M, Abouheba M, Elrouby A, Ibrahim A (2020) Acute intrathoracic gastric volvulus: A rare delayed presentation of congenital diaphragmatic hernia: A case report. Int J Surg Case Rep 70: 123-125. Link: https://bit.ly/3mp3qes

17. Takahashi Y, Seki H (2020) Gastric volvulus with perforation 1 year after total pancreatectomy: a case report. Surg Case Rep 6: 74. Link: https://bit.ly/2HEOqLP

18. Dalgaard JB (1952) Volvulus of the stomach. Acta Clin Scand 103: 131-136.

19. Ismail IB, Zenaidi H (2020) Nécrose gastrique secondaire à un volvulus gastrique compliquant une hernie hiatale. Pan Afr Med J 36: 33. Link: https://bit.ly/3mon1LH

20. Gurala D, Haddad FG, Deeb L (2020) A Case of Intermittent Organo-Axial Gastric Volvulus. Cureus 12: e9387. Link: https://bit.ly/2Tx5069

21. Mistry V, Gamble EL, Chang J (2020) Adult mesentero-axial gastric volvulus: Case report. J Med Imaging Radiat Oncol. Link: https://bit.ly/3ovfT1N
22. Verde F, Hawasli H, Johnson PT, Fishman EK (2019) Gastric volvulus: unraveling the diagnosis with MPRs. Emerg Radiol 26: 221-225. Link: https://bit.ly/2Huf88O

23. Jabbour G, Afifi I, Ellabib M, El-Menyar A, Al-Thani H (2016) Spontaneous Acute Mesenteroaxial Gastric Volvulus Diagnosed by Computed Tomography Scan in a Young Man. Am J Case Rep 17: 283-288. Link: https://bit.ly/35xKMtX

24. Guniganti P, Bradenham CH, Raptis C, Menias CO, Mellnick VM (2015) CT of Gastric Emergencies. Radiographics 35: 1909-1912. Link: https://bit.ly/3703twl

25. Kumar B, Kalra T, Namdeo R, Soni RK (2017) Acute gastric volvulus: A vicious twist of tummy-case report. Int J Surg Case Rep 30: 81-85. Link: https://bit.ly/2HyKSsU

26. Omata J, Utsunomiya K, Kajiwara Y, Takahata R, Miyasaka N, et al. (2016) Acute gastric volvulus associated with wandering spleen in an adult treated laparoscopically after endoscopic reduction: a case report. Surg Case Rep 2 47. Link: https://bit.ly/3dWml7I

27. Gill1 HS, Lubana AS, Bhatia PK, Goel M, Jain P, et al. (2016) Gastric Volvulus as a Surgical Emergency: A Rare Case Report. Sch J Med Case Rep 4: 752-756.

28. Hamid R, Baba AA, Shera AH, Wani SA, Altaf T, et al. (2014) Late-presenting congenital diaphragmatic hernia. Afr J Pediatr Surg 11:119-123.

29. Kishino T, Fukumoto K (2020) Gastric volvulus related to upside-down stomach that was successfully treated by endoscopic repositioning. Dig Endosc 32: e138-e139. Link: https://bit.ly/31lj1gZ

30. Zuiki T, Hosoya Y, Lefor AK, Tanaka H, Komatsubara T, et al. (2016) The management of gastric volvulus in elderly patients. Int J Surg Case Rep 29 88-93. Link: https://bit.ly/2GOCNNI

31. Ueda S, Orita H, Ito T, Tokuda S, Sakuraba S, et al. (2019) A Case of Laparoscopic-Assisted Percutaneous Endoscopic Gastrostomy (LAPEG) for Gastric Volvulus. Case Rep Med. Link: https://bit.ly/3jsRdU8

\section{Discover a bigger Impact and Visibility of your article publication with}

\section{Peertechz Publications}

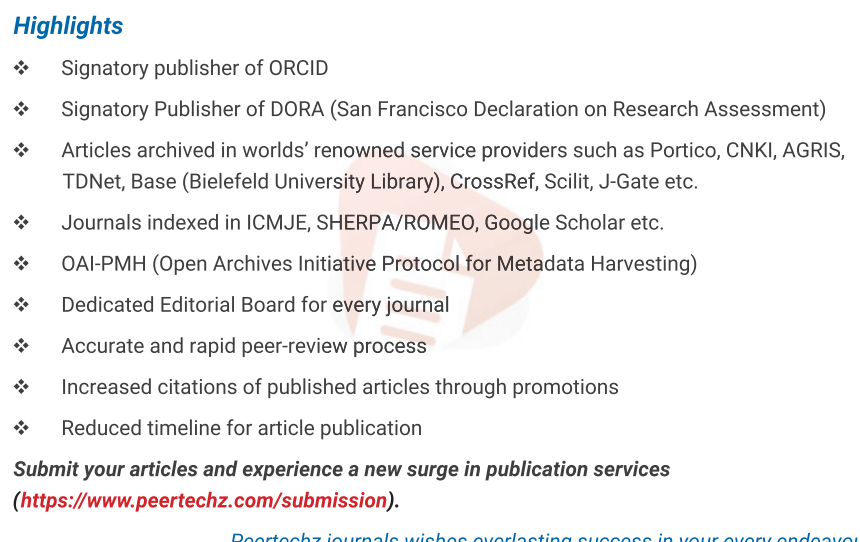

Peertechz journals wishes everlasting success in your every endeavours.

Copyright: ( $) 2020$ Rehman AU, et al. This is an open-access article distributed under the terms of the Creative Commons Attribution License, which permits unrestricted use, distribution, and reproduction in any medium, provided the original author and source are credited.

Citation: Rehman AU, Ikram M, Rauf A (2020) Gastric Volvulus-A Rare Entity. Glob J Medical Clin Case Rep 7(2): 081-084 DOI: https://dx.doi.org/10.17352/2455-5282.000106 